\title{
Ergonomics and design: its principles applied in the industry
}

\author{
Tavares, Ademario Santos ${ }^{\mathrm{a}}$, Silva, Francisco Nilson da ${ }^{\mathrm{b}}$ \\ ${ }^{a}$ Industrial Designer, Universidade Federal de Campina Grande. Adress: Rua da Cruz, $18-1^{\circ}$ andar - MB Jesus, \\ BO 55008-280, Caruaru-Pernambuco, Brazil. (81) 9645-7928.demasantosdesigner@gmail.com \\ ${ }^{\mathrm{b}}$ Materials Engineer, Universidade Federal de Campina Grande. Adress: Avenida prof. Arthur de Sá, 1172 casa \\ 2, Cidade Universitária, BO 50740-520 - Recife-Pernambuco, Brazil. (83)9677-6874.fnilson.s@hotmail.com.
}

\begin{abstract}
Industrial Design encompasses both product development and optimization of production process. In this sense, Ergonomics plays a fundamental role, because its principles, methods and techniques can help operators to carry out their tasks most successfully. A case study carried out in an industry shows that the interaction among Design, Production Engineering and Materials Engineering departments may improve some aspects concerned security, comfort, efficiency and performance. In this process, Ergonomics had shown to be of essential importance to strategic decision making to the improvement of production section.
\end{abstract}

Keywords: ergonomics, production processes, production layout, product development

\section{Introduction}

The activity of Industrial design is too broad and may relate to the entire production chain, ranging from product design to sale, including its disposal and recycling. The multidisciplinary approach allows this profession to work along with other areas of knowledge in order to improve the industrial environment, combining the knowledge and carrying out actions to make production more efficient, safe and functional. The Centro Português de Design [2] highlights the relationship between the designer and the industrial production sector, citing the results of the activity of industrial design are interconnected in a process much bigger than just creating products, and other objects of study disciplines such as Engineering and Business management techniques.

In this context three important elements are included: man, machine and environment. They are a system that is considered the basic unit for ergonomics studies. Therefore, there is a strong relationship between industrial design and ergonomics.

This article will present a case study of an industry that brought together the departments of Industrial Design, Production Engineering and Materials Engineering aiming to improve the production process of one of its products by applying the principles of Ergonomics. The industry is located in the city of Paulista, Pernambuco, Brazil, which develops and manufactures medical artifacts.

The taken procedures led to the development of new working tools and reengineering of the assemble sector. As a consequence of that study, operators' complaints about muscle fatigue were reduced, time spent in manufacturing the product decreased, production increased and product assembly steps shown greater efficiency.

\section{Methodology}

The Approach to Human-Task-Machine System based on the procedures proposed by Moraes and Mont'Alvão [6] were used to perform the analysis. This approach looks for understanding the problems faced by the industry, mapping them as a way to propose improvement solutions. Participatory Ergonomics Techniques demonstrated in Fialho and Santos [4], were also used. These techniques aim to get information from operators, taking into consideration their opinions on the production system and work environment. From an overview to specific situations 
for improvements the analysis were taken. There were two phases of analysis:

General Analysis - The industry prepares performance reports every year. The main goal is to get an overview of their activities and compare current results with those from previous years to develop improvement strategies. Professionals from various fields of studies such as industrial design, production engineering, materials engineering, civil engineering, machine maintenance staff, logistics, packaging, sterilization industry, etc., take part in that event. Aspects regarding production, functionality of sectors, performance of the departments, internal communication, etc. are then analyzed. If any department is generating lower than expected results, more specific and detailed analysis are made just to those departments.

Specific analysis - Based on the overview diagnostics, more detailed analysis are taken along the operators who are directly involved with the sector that shows the failures. A team of professionals carries out studies and thorough testing seeking solutions that would preclude or minimize the problems encountered.

In this case study, the analysis used to detail the diagnosis and design improvements were divided into two steps:

\subsection{Step 1 - Analyzing the working environment}

At this stage different situations were analyzed: flow activities were detailed, assemble procedure layout, available space for operators' movements and accessibility, goods flow, assemble line sequence, ventilation, lighting, hygiene, thermal and acoustic comfort, internal communication, etc.

\subsection{Step 2 - Analyzing the task}

It consists in detailing the activity performed on the working station, inspecting its various aspects such as operator's position, frequency of equipment use, functional grouping, efforts in performing the task, task sequence, safety and comfort in the workplace, production speed, etc.

In both cases, comments about performing the task and what could negatively influence its implementation were considered. Some situations are related to both tests, after all, one depends on another so that the system can function satisfactorily.

Questionnaires were handed out to operators so that they could express their points of view on the working environment and equipment and also propose solutions for improvements. Although all these aspects influence the system performance, aspects concerning human factors were the most important.

Searching to adapt working to man, it was necessary to develop some tools that would facilitate performing the task by operators. At this stage of product development, design methodology principles suggested by Bonsiepe [1] were adapted to the company's reality. A sequence of activities was established and basically divided into:

- Problem definition;

- Tasks analysis and operators' opinions;

- Project requirements list;

- Ergonomics and Anthropometrics studies;

- Brainstorming and Sketches;

- Functional mock-ups;

- Preliminary tests;

- Revisions;

- Implementation of new products.

\section{Improvements implementation}

After a detailed diagnostic through specific analysis, some situations that obstacle a good performance in the assemble sector of a new product developed by the company that was already on the market were found. The product will be referred in this article as "product X". The diagnosis identified the following situations:

- Lack of organization in the distribution of working stations;

- Difficulty in transporting the components and moving operators;

- Loading transportation done manually;

- Inappropriate body movements;

- Repetitive and stressful work;

- Inadequate handling of components;

- Risks of minor accidents during the transportation of components.

It was found that, in the long run, such situations would contribute to lower production and threaten to rise disorders and repetitive stress injuries to operators. The previous questionnaires answered by operators, reported physical discomfort they felt at the end of a working day. The problems were classified into several categories according to Soares [7], such as moving, displacements, spatial, operational and action. As diagnostics were finished, two steps for improvement were set to run: 
Working station reengineering layout - In this context, working stations are considered as a workstation consisting of table, chair and specific equipment to perform the necessary task.

New products - Development of some tools that would make operators' work and performance easier.

\subsection{Analyzing the task}

Before any changes were done, all the operations carried out in the assemble sector that happens in two rooms were identified. The assemble sequence of "product $\mathrm{X}$ " is as follows:

- Room 1

* Step 1 - Write the measuring scales on component 1;

* Step 2 - Inspection and drying of the component. Bring a box with component 1;

* Step 3 - Glue piece 1 on the component 1;

* Step 4 - Inspection and drying of component 1 . Bring box with the piece 1 ;

* Step 5 - Glue piece 2 to component 1;

* Step 6 - Inspection and drying of a component 1 . Bring box with piece 2 .

- Room 2

* Step 7 - Glue hose to component 2;

* Step 8 - Inspection and drying of component 2. Bring box with hose and connector 1;

* Step 9-Fit connector 1 to component 2;

* Step 10 - Transport component 2 to room 1. - Room 1

* Step 11 - Assemble component 1 to component 2 and pack set.
The activities identified as "Bring the box to" refer to the transportation of components or parts from the manufacturing sector to assemble sector and only occurs when the number of components or some part is running out on the working station. While executing steps 2, 4, 6 and 8, the operator stops his task and leaves his place of work to fetch a box of components in manufacturing sector. An operator in the assemble sector helps him. In this case, there are 15 operations in 11 steps, with four breaks for transporting goods.

According new proposed layout, assemble processes are performed in just one room, reducing operator's movement in the assemble sector. With the carrack, the four operations to bring the components from the manufacturing sector could be realized now by only the operator in the manufacturing sector, allowing assemble operator to do focus on its activity. These changes decreased 25 seconds in achieving steps 2, 4, 6 and 8 , due to a faster performance in transporting components.

Figure 1 below shows three images. The first one on the left, is the new proposal for the layout with the new location of working stations in room 1, indicating 11 steps to assemble "product X". There are two assemble sequences (steps 1 to 6 and steps 7 to 9 ), which correspond working station 10, where components 1 and 2 are put together. In working place 11 , product is packed before being sent to the final inspection room. The image in the center shows the room with the new layout. The third image on the right shows the car rack that was designed to carry the components.
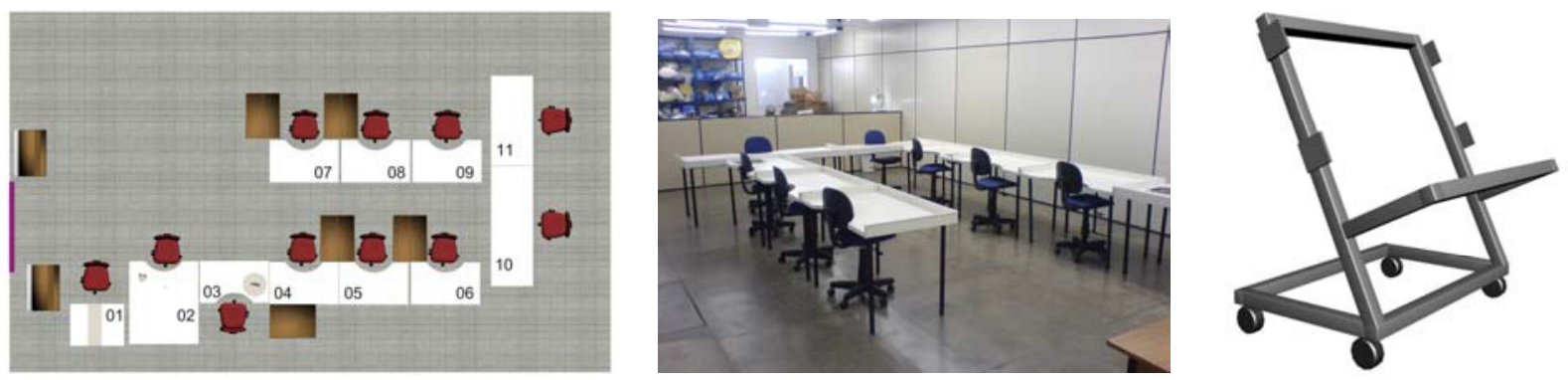

Fig. 01: New interior design layout (left), photo from the assemble sector to "product X" (center) and car-rack design with casters (right).

\subsection{New products development}

To develop new products a group of professionals from different sectors was necessary such as: indus- trial designer, product manager, materials engineer, tooling operators and assembly operators. This teamwork was essential. Five new products were then developed: two tables for working stations, two 
artifacts and the car-rack to transport components. All new products were manufactured in-house.

The basic procedures of design methodology by Bonsiepe [1] were of great importance to the development of products. The issues related to anthropometric measures of reaching, handles and handling, as well as height and distance in the working place have been obtained through researching and testing based on data information by Tilley and Henry Dreyfuss Associates [3]. The designed products should meet specific operators' needs. Therefore, several models were designed for testing, which were examined by operators until functional and appropriate models correspond to each activity.

\subsubsection{Car-rack}

The car-rack was developed using square metal profiles and pulleys. Its structure was designed to facili- tate usability by the operator who pushes it as well as the one who is seated and uses components that are inside the boxes positioned on the car. After several tests, a satisfactory height was achieved, preventing inadequate efforts and rotations to operators' column.

\subsubsection{Working station tables}

The designed models have similar configuration to the existing tables, but the changes allowed a larger space on its surface and a more efficient distribution of equipment. The material used was wood coated in melamine laminate, which allows easy cleaning.

Figure 2 below shows three images: the first one, displays a 3D model of the car-rack and one of the boxes it holds (left). The center image shows a sample table, and the third image on the right shows the working stations 01 and 02 and the car-rack.
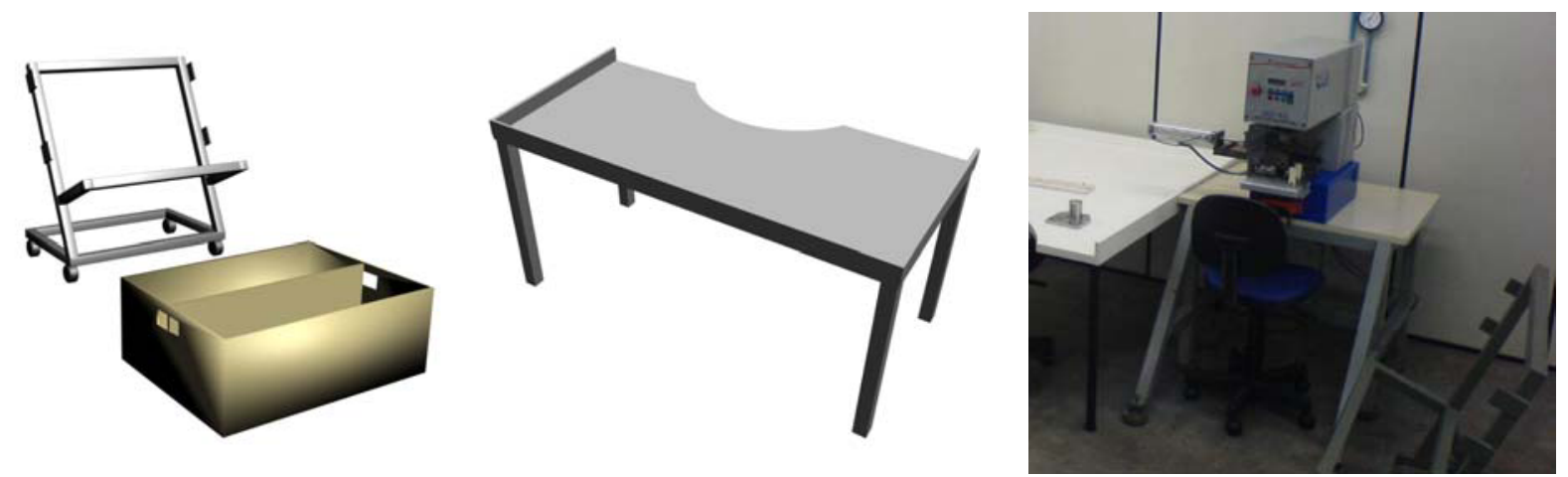

Fig. 02: Car-rack and box (left), a working table (center). Working station 01 and 02, and car-rack (right)

\subsubsection{Assembly tools}

Two artifacts were designed to facilitate assembling two product components which have small dimensions. The new tools facilitate the assemble on steps 03 and 07. As the assemble is done manually, the process takes a certain time to run and requires concentration and precision by the operator. To play safe, the operator performed the task slowly, which increases the assemble time and required a greater effort for its realization.

The principles of Ergonomics and Anthropometry were studied and applied to the development of these two tools, since they are strongly related to operators' usability. To fulfill the needs required for the task, some design requirements for the tools were established. That is, the products should:

- Allow a firm and precise handling, without risk of slipping in the act of assembling;

- Be made out of a material that allows an easy and quick cleaning;

- Be resistant to the efforts which that will be submitted during the tasks;

- Avoid scratches or scuffs to the components that are being assembled;

- Be easy to manufacture.

It is believed that the use of two tools increases the precision in fitting, and in addition decreases the time and efforts spent by operator to perform its task, since it allows a more comfortable and accurate handle. Studies to determine measures coverage and reaches, angle of movement, applied effort, precision 
fitting, were carried out. Several usability tests were conducted in order to achieve a solution that would be suitable to operators. The appropriated material to be used for the manufacturing the tools has been studied by materials engineering department, who selected Teflon, due to its physical and chemical characteristics. All materials were available in the industry.
Figure 03 shows two tools (white) that were designed and the components that they assist in the assembling task. The left image shows the instrument (white) along with the assemble component to step 03 (blue). Picture in the center shows the tool (white) and hoses used to step 07 . The third image shows an operator performing their task using the new tool.

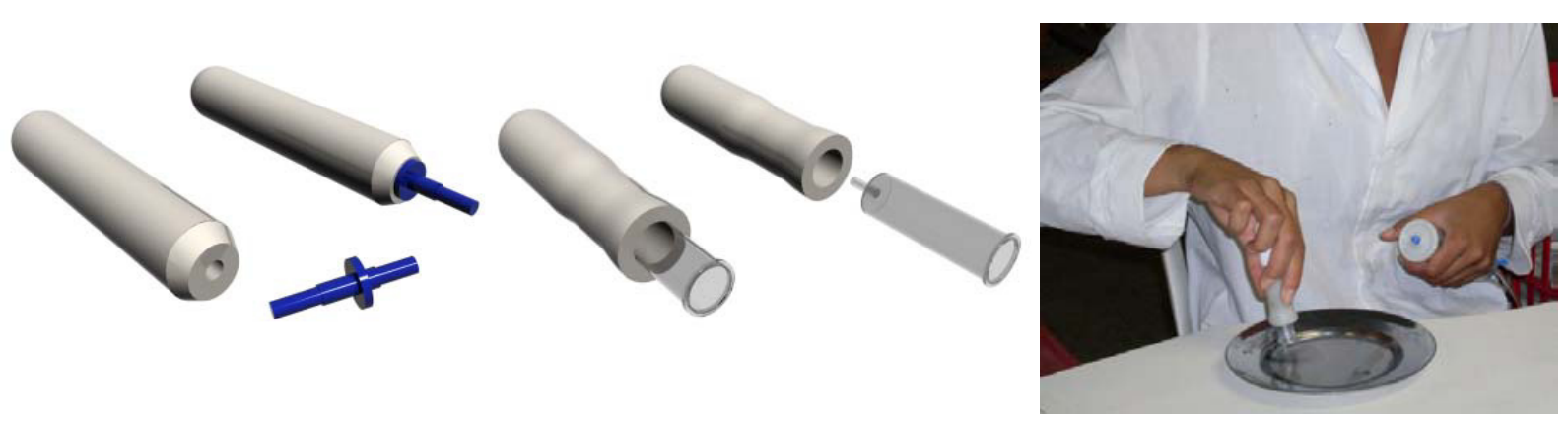

Fig. 03: Manual tool developed (white) and product component blue and transparent. And operator using the tool (right)

\section{Results}

The results were satisfactory and operators have proved enthusiastic about the improvements. The concentration of activities in just one room increased integration among operators and new tools increased production as well as the precision and comfort to perform the tasks in the working sites. That is, both new layout and new five products achieved the outlined objectives: to generate improvements to the productive process and operators' working stations. Even operators who felt some discomfort while they performed their tasks did not complain anymore.

In order to compare the efficiency of the achieved results time measurements were performed before and after the implementation of the changes, so that they could investigate the impact of improvements in the assemble sector. Initially, the assemble operation for "Product X" totaled 15 steps shared into 11 workstations. The average time spent on this task was 3 minutes and 4 seconds. This time was measured from the arrival of a component 1 on the working station 01 to the final process of packing on working station 11.

The changes have reduced the average time to 1 minute and 15 seconds in total running assemble. Therefore, the average time for assembling the product was reduced to 1 minute and 49 seconds. A very important improvement to production process.

Before setting improvements, daily production of "Product X" average was 300 units. After changes, the industry can produce 700 units per day. Regarding monthly production, the industry increased from 6,000 to 15,000 units. These results confirm the improvements obtained according the proposed interventions.

\section{Conclusions}

Once again, the Ergonomics proved being effective in identifying and solving problems. Its closeness to industrial designer activities and to manufacturing sector strengths its preventive and transforming character, making the working environment more appropriated, efficient and secure. In other words, improving the quality of human life.

We can conclude that ergonomics techniques can be satisfactorily applied to industrial environment to increase not only the quantity of production, but also the quality and efficiency of activities and working sites. According this case study, satisfaction and motivation of operators in the assemble sector greatly increased because they felt their needs were fulfilled. The interaction among operators and their senior 
leaders was also very important and were favored due to the techniques of participatory ergonomics.

In this case, the designers' perception along with the knowledge of ergonomics, production processes and available materials used by the company, enabled the implementation of changes that have produced a quite relevant effect. The interaction among man, his working tool and the environment in which he operates is an essential factor. Thus, efficiency in production can be obtained, generating income and better welfare for its employees while increases the quality of the product.

\section{References}

[1] Bonsiepe, G. (coordenador) - Metodologia Experimental: Desenho Industrial - Brasília, CNPq/Coordenação Editorial, 1984.

[2] Centro Português de Design. Manual de Gestão do Design. Porto: Porto Editora, 1997.

[3] Tilley, A. and Henry Dreyfuss Associates. As Medidas do Homem e da Mulher. São Paulo: Bookman Companhia Ed. 2005.

[4] Fialho, F. A. P. and Santos, N. dos. Manual de Análise Ergonômica no Trabalho. 2.ed. Curitiba: Gênesis, 1997.

[5] Iida, I. Ergonomia: projeto de produção. São Paulo: E. Blucher, 2001;

[6] Moraes, A. and Mont'Alvão, C. Ergonomia: conceitos e aplicações. 3a. ed. Série Design. Rio de Janeiro, Editora 2AB, 2003;

[7] Soares, M. M. Ergonomia: Princípios, Métodos e Técnicas. Universidade Federal de Pernambuco: Recife, 2009. Curso de Extensão em Ergonomia: Princípios, Métodos e Técnicas. 01 de set. 2009 a 31 de out. 2009. Notas de aula. 